\title{
A Educação Ambiental Crítica e suas relações com as Ações
}

\author{
Afirmativas \\ Educación Ambiental Crítica y sus relaciones con Acciones Afirmativas \\ Critical Environmental Education and its Relations with Affirmative \\ Actions
}

\author{
Daniele Barros Jardim ${ }^{1}$ \\ Humberto Calloni²
}

\begin{abstract}
Resumo
Esta escrita possui como objetivo refletir sobre o que é Educação Ambiental Crítica e suas relações com as Ações Afirmativas, pois entendemos que a Educação Ambiental - EA é uma das vias para ocorrer o desenvolvimento de uma transformação social. Para tanto realizamos uma revisão bibliográfica a fim de interpretar estas relações, utilizando autores como Sauvé (2005), Loureiro (2004) e Fonseca (2009). Dessa forma, as Ações Afirmativas encontra-se intrinsicamente relacionadas à proposta de Política Nacional de Educação Ambiental (1999), uma vez que suas ações destinam-se a assegurar, mediante a educação, a integração das múltiplas dimensões da sustentabilidade como: ambiental, ética, cultural, econômica, espacial e política.
\end{abstract}

Palavras-Chave: Educação Ambiental Crítica; Ações Afirmaivas; Transformação Social.

\section{Resumen}

Este escrito tiene como objetivo reflexionar sobre lo que es la Educación Ambiental Crítica y su relación con las Acciones Afirmativas, porque entendemos que la Educación Ambiental - EA es una de las formas de desarrollar una transformación social. Por lo tanto, realizamos una revisión de la literatura para interpretar estas relaciones, utilizando autores como Sauvé (2005), Loureiro (2004) y Fonseca (2009). Por lo tanto, las acciones afirmativas están intrínsecamente relacionadas con la propuesta de la Política Nacional para la Educación Ambiental (1999), ya que sus acciones están destinadas a garantizar, a través de la educación, la integración de múltiples dimensiones de sostenibilidad, tales como: ambiental, ética, culturales, económicas, espaciales y políticas.

Palabras claves: Educación Ambiental Crítica; Acciones Afirmativas; Transformación Social

\begin{abstract}
This writing aims to reflect on what is Critical Environmental Education and its relations with Affirmative Actions, because we understand that Environmental Education - EA is one of the ways to occur the development of a social transformation. To do so, we perform a bibliographic review to interpret these relationships, using authors such as Sauvé (2005), Loureiro (2004) and Fonseca (2009). Thus, Affirmative Actions are intrinsically related to the proposal of the National Environmental Education Policy (1999), since its actions are intended to ensure, through education, the integration of the multiple dimensions of sustainability as: environmental, ethical, cultural, economic, spatial and political.
\end{abstract}

\footnotetext{
${ }^{1}$ Doutoranda em Educação Ambiental; Universidade Federal do Rio Grande - FURG; Rio Grande, Rio Grande do Sul, Brasil; danielejardim@furg.br

${ }^{2}$ Doutor em Educação; Universidade Federal do Rio Grande - FURG; Rio Grande, Rio Grande do Sul, Brasil; hcalloni@mikrus.com.br.
} 
Keywords: Critical Environmental Education; Affirmative Actions; Social Transformation.

\section{Considerações Iniciais}

Esta escrita possui como objetivo refletir sobre o que é Educação Ambiental Crítica e suas relações com as Ações Afirmativas, pois entendemos que a Educação Ambiental - EA é uma das vias para ocorrer o desenvolvimento de uma transformação social. E essa transformação de cunho emancipatório, articulada ao exercício da cidadania se torna coerente com as mudanças sociais.

A Educação Ambiental que se propõe ser crítica, precisa necessariamente de um projeto de educação vinculado a uma política de transformação social, na perspectiva de uma práxis que caminhe para o processo de reorganização do mundo e da autotransformação humana. Logo, é preciso uma prática pedagógica que consiga agir, compreender de forma crítica e criativa essas transformações e desenvolvimentos, o que no caso entendemos que possa ser as Ações Afirmativas.

Dessa forma, as políticas de Ações Afirmativas são praticadas para minimizar as desigualdades em sua maioria históricas, oportunizando equidade de oportunidades as pessoas e/ou grupos, bem como de reparar privações provocadas pela discriminação e marginalização, decorrentes de motivos sociais, raciais, étnicos, religiosos, de gênero entre outros (FONSECA, 2009). E encontra-se intrinsicamente relacionada à proposta de Política Nacional de Educação Ambiental (1999), uma vez que suas ações destinam-se a assegurar, mediante a educação, a integração das múltiplas dimensões da sustentabilidade como: ambiental, ética, cultural, econômica, espacial e política.

Para tanto, utilizamos a pesquisa bibliográfica como metodologia desta escrita, pois realizamos um levantamento de referências teóricas já analisadas e publicadas, nos permitindo conhecer mais sobre o assunto (MINAYO, 2010).

Contudo, após 40 anos de luta pela democracia, no qual governos autoritários estavam no comando e que lutas ecológicas entravam em cena, hoje estamos retrocedendo às mesmas lutas. Voltamos ao campo inicial de preocupações e ações sociais, que surgiram como crítica à sociedade de consumo. Vivemos numa sociedade em conflito (GADOTTI, 1989), que duas forças contrárias medem seu poder o tempo todo, como o conflito de gritar e a coragem de ser, como a liberdade e a opressão, que marcham sobre momentos históricos, sem certezas de onde vamos parar. 
Ao estudar e conhecer as várias vertentes de conceber e praticar a ação educativa neste campo da Educação Ambiental - EA partilhamos dos ideais da corrente crítica (SAUVÉ, 2005), pois são ideais democráticos e emancipatórios, que estimulam a participação e o exercício da cidadania. Isto é, faz com que a EA que queremos seja mais do que nunca crítica, uma vez que se nega a ser politicamente neutra indo além das consequências da crise ambiental que tanto falamos.

A corrente crítica da EA se baseia em alguns ideais humanistas, que refletem criticamente sobre seu ambiente concreto, sua realidade, tornando os sujeitos gradualmente conscientes e comprometidos, tornando-se capaz de intervir e transformar o mundo. Nestes termos, esta deve defender um modelo de educação vinculado a um projeto de transformação social e de autotransformação humana, mediante uma compreensão crítica, como também criativa do mundo.

Logo, vivemos em um momento de agir na história, na busca permanente pela sociedade que queremos, com enfoque na reflexão sobre o funcionamento dos sistemas sociais e assumindo uma postura dialógica (FREIRE, 1987). Acreditamos que a educação é um investimento formativo do ser humano, seja na relação pessoal ou no âmbito da relação social, isto é, a educação é uma ação social, pois só nos educamos em contato com o outro e nas relações com os demais indivíduos da sociedade.

Nas próximas sessões, abordaremos inicialmente os princípios e as concepções de uma Educação Ambiental Crítica que se estabelecem em seus fundamentos e em seguida as aproximações desta com os elementos históricos, epistemológicos e sociológicos das Ações Afirmativas, buscando compreender esse processo de transformação social, como se dá a tomada de consciência e a emancipação humana.

\section{Como conceber, praticar e compreender a Educação Ambiental Crítica}

Hoje, a Educação Ambiental - EA é extremamente importante para desenvolver a capacidade crítica, num processo de reflexão sobre a vida e a natureza, criando estados de liberdade diante as condições e propiciando alternativas para irmos além (LOUREIRO, 2004). Concebê-la dessa forma, é pensar na EA como promotora da humanização de sentidos humanos, que estabeleça a tomada de consciência e a emancipação humana, bem como a superação de todas as formas de opressão.

Contudo, nesse contexto é necessário falar em refundar os fundamentos da EA, pois certos conceitos e categorias estão passando por um esvaziamento de sentidos. Isso porque 
falsos consensos da questão ambiental precisam ser superados pelos educadores ambientais. Compartilhamos, neste caso, das ideias de Paulo Freire (1987), que nos ajudam a compreender que a superação do senso comum só será possível mediante uma postura dialógica, que consequentemente gera transformação.

Logo, a EA deve ser crítica por princípio, em seus fundamentos, nos mobilizando diante dos problemas e ajudando numa ação coletiva transformadora (LOUREIRO, 2004). Segundo Vasconcellos (2002) a presença, em todas as práticas educativas, da reflexão sobre as relações dos seres entre si, do ser humano com ele mesmo e do ser humano com seus semelhantes é condição imprescindível para que a EA crítica ocorra.

Pensamos que a educação em si já é uma necessidade ontológica da nossa espécie, mas a adjetivação ambiental se justifica por destacar e resgatar dimensões esquecidas do fazer educativo, enquanto a segunda adjetivação, crítica, denomina a possibilidade de se fazer. $\mathrm{Na}$ tentativa de compreendermos o mundo pela criticidade, se faz necessário uma visão de mundo que nos coloque como sujeitos de nosso quefazer e não como meros espectadores deste.

Nesse sentido, isso significa fazer uma transformação integral de nossa existência, conhecendo a realidade, atuando e superando as relações de dominação e opressão entre humanos e natureza, buscando igualdade e justiça social. Mas, neste percurso é preciso cuidar para não cair nas armadilhas paradigmáticas (GUIMARÃES, 2004), como por exemplo, a justificativa sobre o desenvolvimento sustentável que é bem diferente de sustentabilidade. Desenvolvimento sustentável, por exemplo, é usado pelo modelo capitalista, o qual "preserva" sem deixar de atender as necessidades econômicas e o desenvolvimento econômico. Enquanto a sustentabilidade estabelece um equilíbrio entre o que a natureza oferece e nosso limite de consumo.

Corroboramos com as premissas de Guimarães (2004) sobre a necessidade de formação de educadores ambientais críticos para superar a crise socioambiental que vivemos, no qual o ambiente educacional deve ter numa perspectiva problematizadora, assumindo limitações e capacidades em busca de novas lideranças. Para o autor, a prática educativa da EA não se realiza sozinha, mas nas relações, nas interações conduzidas por um sujeito.

Sustentabilidade atualmente é um termo utilizado para orientar um princípio de práxis humanas, sem comprometer os recursos naturais e o futuro das gerações vindouras e surge em um contexto de preocupação global sobre o ambiente. Contudo essa expressão vem sendo uma "armadilha paradigmática" (GUIMARÃES, 2004), na qual as pessoas devido a uma visão simplista da realidade reproduzem práticas conservadoras, inconscientes, acreditando que é uma prática transformadora, em nome de um desenvolvimento sustentável. De acordo 
com Leff, o princípio da sustentabilidade surge para repensar o processo econômico que estamos inseridos, conceituando-a como a sustentabilidade é uma maneira de repensar a produção e o processo econômico, de abrir fluxo do tempo a partir da reconfiguração das identidades, rompendo o cerco do mundo e o fechamento da história impostos pela globalização econômica. (LEFF, 2010, p. 31).

Pensando nesse sentido, precisamos de uma "racionalidade ambiental" (LEFF, 2006), que seria a reapropriação social da natureza, que orienta os processos e ações sociais, para a desconstrução da racionalidade econômica. E isso vai de encontro com a tal necessidade que orienta os processos econômicos, sob a justificativa da melhoria da qualidade de vida.

Logo, o princípio de sustentabilidade vem sendo abordado em inúmeros documentos a fim de orientar as práxis ambientais no mundo. Na Declaração de Estocolmo (1972), percebemos que a questão da sustentabilidade perpassa praticamente todos os princípios descritos de certa forma, pois buscam orientar os processos a fim de manter um ambiente ecologicamnete equilibrado e garantir a conservação do ecosistema. Como exemplo, trazemos o princípio de número 18 "Como parte de sua contribuição ao desenvolvimento econômico e social deve-se utilizar a ciência e a tecnologia para descobrir, evitar e combater os riscos que ameaçam o meio ambiente, para solucionar os problemas ambientais e para o bem comum da humanidade".

Entre as recomendações da Conferência de Tbilizi (1977), a partir dos princípios básicos nela citados, entre eles o de "Considerar, de maneira explícita, os aspectos ambientais nos planos de desenvolvimento e de crescimento" se busca que a Educação Ambiental deveria contribuir para o desenvolvimento de um espírito de responsabilidade e de solidariedade entre os países e as regiões. Esse fundamento, de uma nova ordem internacional que garanta a conservação e a melhoria do meio ambiente, bem como que uma atenção particular deverá ser dada à compreensão das relações complexas entre o desenvolvimento socioeconômico e a melhoria do meio ambiente, está diretamente relacionado com o princípio da sustentabilidade, tendo em vista que as indústrias passaram a usar desenfreadamente os recursos naturais, ocasionando uma enorme degradação ambiental.

No tratado do evento da RIO-92 (1992), a sustentabilidade toma uma conceituação na introdução do documento no qual considera a Educação Ambiental, para uma sustentabilidade equitativa, como um processo de aprendizagem permanente, que se baseia no respeito a todas as formas de vida e que contribui para uma transformação humana e social, bem como para a preservação ecológica. E dentre seus princípios da educação para as sociedades sustentáveis, 
no de número dois ressalta que todas as oportunidades de experiências educativas deve ter como base sociedades sustentáveis.

Na PNEA (1999), em seu artigo $1^{\circ}$ que define Educação Ambiental, traz o princípio de sustentabilidade como orientador dos processos. No artigo $4^{\circ}$, que trata dos princípios básicos, o de número II reforça o enfoque da sustentabilidade a partir da conceituação de meio ambiente como totalidade, bem como no artigo $5^{\circ}$ que apresenta os objetivos fundamentais da EA, em seu ítem V que trata do estímulo à cooperação entre as regiões do Brasil, que visa uma sociedade socialmente equilibrada, por meio de inúmeros princípios dentre eles o da sustentabilidade.

E o documento das Diretrizes Curriculares da Educação Ambiental (2012) que faz referência aos princípios e objetivos da PNEA (1999), bem como aos documentos supracitados, destaca entre os motivos para estas diretrizes ocorrerem, que o princípio da sustentabilidade está vinculado a uma proposta de mudança de visão de mundo e de reposicionamento dos seres humanos ao atual modelo econômico, em diversas áreas do conhecimento e de produção.

Mediante a busca de novas compreensões e discussões sobre o ser humano e natureza é necessário refletir sobre a redefinição do espaço humano no cosmos (PEREIRA, 2016). Nessa perspectiva, o lugar da EA é um espaço de denúncias e anúncios, em todos os lugares e para todos, mas principalmente aos excluídos. Estes por sua vez, que são a base da sociedade são usados como mão de obra para o dito "desenvolvimento sustentável", e a sociedade dominante lhes nega esclarecimentos justamente para não conhecerem e ficarem a mercê do que ditam.

Por isso, pensamos que os estudos no campo da Educação Ambiental Crítica nos ajudam a pensar e agir no horizonte dessa crise ambiental que estamos imersos, pois pensamento e realidade colaboram na compreensão do mundo como um todo e é a forma mais eficiente para atingir as pessoas, por causa da expansão de sentidos que acarretam mediante os movimentos históricos e suas condições materiais de vida.

Essa transformação no campo da EA se dá desde a década de 60, com a publicação do livro "Primavera Silenciosa" de Rachel Carson (1962), uma vez que deu início ao despertar da consciência pública ambiental e já temia que o avanço tecnológico, fosse maior e mais rápido que o senso de responsabilidade moral.

Nessa perspectiva, Enrique Leff (2006) já orienta para a necessidade de uma racionalidade ambiental, diante dessa crise ambiental que aponta limites e nos apresenta demandas como democracia, equidade e justiça social. O referido autor explica que existem 
duas problemáticas contemporâneas, uma é a crise da racionalidade econômica e a outra é crise teórica da modernidade, que exigiram a consciência sobre a fragmentação do conhecimento, mediante um enfoque sistêmico e um conhecimento holístico, inicialmente, para a busca de uma nova racionalidade social, isto é, para uma reapropriação social da natureza ou ainda um saber ambiental, mediante a epistemologia ambiental.

Buscando interpretar o que Leff nos coloca apresentamos um esboço de alguns conceitos trazidos nessa premissa, a fim de compreender esse saber que corresponde ao ambiente e que problematiza a nossa racionalidade atual para uma racionalidade ambiental, nos ajudando a pensar criticamente.

A racionalidade econômica é decorrente de uma economia neoliberal que defende a não participação do estado na economia, onde deve haver total liberdade de comércio, para garantir o crescimento econômico e o desenvolvimento social de um país, e por consequência, permiti práticas nocivas, poluentes e degradantes ao meio ambiente. A racionalidade econômica atribuiu um padrão de produção e consumo predispostos a satisfazer necessidades ideologicamente enganosas, o que acarreta uma ruptura da relação intríncica entre homem, sociedade e ambiente.

A crise teórica da modernidade é a persuasão de que a razão é um princípio unificador verdadeiro, amparada num método científico de base humana racional. Logo, quando não se revelou como verdadeira gerou a crise, provocando um desiquilíbrio nas relações humanas fazendo com que as pessoas buscassem o sucesso independente da condição do outro, seja humana ou natural, provocando uma ruptura com o pensamento da coletividade e do bemestar social. No mesmo período surgiu a Ciência Moderna que apesar de possibilitar algumas elucidações, provocou uma grande ruptura entre o saber popular e o saber científico.

Dessa forma, compreendemos que a questão ambiental no campo do desenvolvimento e a interdisciplinaridade no campo do conhecimento, são algumas das estratégias conceituais do saber ambiental que visa reunificar a realidade da degradação ambiental, bem como da desigualdade social em meio as crises contemporâneas.

Para Leff, a questão ambiental é a complexidade do mundo, são as formas de apropriação deste através das relações de poder que estabelecemos, "o discurso ambiental questiona os paradigmas estabelecidos das ciências para internalizar um saber orientado pela construção de uma nova racionalidade social" (p.168, 2002). E a interdisciplinaridade se constituiu como um modo específico na busca da refuncionalização dos saberes, pois é um processo de reconstrução social através de uma transformação ambiental de conhecimento “...a interdisciplinaridade adquiriu um caráter técnico na refuncionalização dos saberes 
existentes levados a uma política de ajustes do conhecimento para reordenar a realidade existente" (p. 167, 2002).

É importante destacar que para Leff o ambiente é o Outro nessa desconstrução da racionalidade estabelecida e obtém o saber como foco dessa reflexão, abrindo espaço para a relação do Ser com o saber em busca de novos horizontes, bem como novas formas de ver e ser o mundo. Dessa forma, o saber ambiental coloca-se fora da ideia de visões sistêmicas. A noção de sistemas no âmbito de uma Teoria Sistêmica surgiu na primeira metade do século XX, contrariando o método científico definido por René Descartes. E essa abordagem de pensar no todo, ganha a noção de ambiente e por isso necessitou se de uma ciência holística e interdisciplinar.

Contudo, o saber ambiental "ultrapassa o campo da racionalidade científica e da objetividade do conhecimento" (Leff, 2002), se constituindo numa nova racionalidade teórica, que é de onde emergem as novas estratégias conceituais como a revalorização de saberes populares que a ciência moderna abortou, assim como novos princípios e valores:

A racionalidade ambiental inclui novos princípios teóricos e novos meios instrumentais para reorientar as formas de manipulação produtiva da natureza. Esta racionalidade está sustentada por valores (qualidade de vida, identidades culturais, sentidos da existência) que não aspiram a alcançar um status de cientificidade. Abre-se dessa forma um diálogo entre ciência e saber, entre tradição e modernidade. Esse encontro de saberes implica processos de hibridação cultural (García Canclini, 1990) onde se revalorizam os conhecimentos indígenas e os saberes populares produzidos por diferentes culturas em sua coevolução com a natureza (LEFF, p. 168 e 169, 2002)

Podemos dizer que a ciência não é e dificilmente será objetiva, pois têm verdades mais apropriadas que outras, que vai depender de inúmeros fatores que atravessarão esse processo, seja ético, metodológico, subjetivo entre outros. Ao mesmo tempo, não existe um processo livre de subjetividade, por isso precisamos utilizar estratégias eficazes para validar essa objetividade do conhecimento científico, pois a ciência não parte do inexistente e exatamente por esse motivo a objetividade continua sendo ambicionada.

Com relação à questão da diversidade cultural, isto é, ao encontro do diálogo de saberes -hibridação cultural- gerados por estes novos princípios e valores, é preciso ficar atento para que este não seja a representação de culturas com velhos processos de princípios e de valores que levam ao consumo e ao sistema capitalista. Por este motivo, é importante pensar em estratégias que não caminhem para perpetuar a ruptura da relação homem, cultura e ambiente. Nessa constituição na relação com o ambiente, o saber ambiental se propõe a transformar conceitos e métodos, articula a interdisciplinaridade do saber ambiental e gera 
novas estratégias, mediante teorias e técnicas.

Sendo assim, Leff (2002) interpreta que o saber ambiental emerge dessa razão só que de uma forma crítica, quando leva o sujeito a buscar um novo posicionamento frente às questões ambientais, internalizando a dimensão ambiental no campo das ciências, refletindo sobre a importância dos diálogos entre os saberes/conhecimentos e discutindo a reformulação de valores e ideologias a fim de reconfigurar as identidades. Uma vez que todos estes processos desconstruíram a racionalidade que levaram o mundo à crise ambiental que presenciamos.

Assim, a resistência ao neoliberalismo se torna um conflito ambiental e somente mediante uma sinergia que conseguiremos desconstruir a racionalidade econômica para assim iniciarmos um processo de reapropriação social e ambiental.

Como a Educação Ambiental possui a incumbência de ajudar a problematizar as questões sócioambientais, contemporâneas entre as pessoas, nada mais sensato do que abranger os princípios da Educação Ambiental no trabalho pedagógico, a fim de potencializar a capacidade crítica, criativa e de transformação, isto é, visando um novo comportamento do ser humano no meio, amparado em critérios socioambientais.

Segundo Loureiro (2004), a problemática central de se retomar tal reflexão sobre os fundamentos da Educação Ambiental não é estabelecer um modelo padrão para ser orientador aos educadores ambientais, pois isso geraria um reducionismo e uma negação do educar como processo dinâmico. Ao contrário, ele entende e compreeende que devemos:

Objetivamos, sim, definir as premissas que fundamentam uma tendência crítica que enfatiza a Educação Ambiental como uma visão paradigmática diferenciada da e na educação e que, pela explicitação do contraditório, torna compreensível os diferentes modelos encontrados em projetos e programas formais, informais e não formais (LOUREIRO, 2004, p. 21).

Portanto, é importante a apresentação de diversos conceitos em Educação Ambiental que podem e devem ser confrontados democraticamente mediante o diálogo, ocasionando uma demarcação dos diferentes campos teóricos que orientam a mesma em suas múltiplas abordagens. Parafraseando Loureiro (2004), a ideia de que tudo é válido, desde que se tenha em mente a preservação do ambiente, não promove a transformação que desejamos para viver em sociedade da forma como almejamos, nem mesmo para nos sentirmos como parte da natureza.

Existe a constatação da instituição de um modelo de Educação Ambiental que tem como enfoque a reflexão sobre o funcionamento dos sistemas sociais, em que esse novo modelo, segundo Layrargues \& Loureiro, "busca cada vez mais uma aproximação mais 
realista e complexa da articulação da pauta ambiental com a social" (2000, p.6). Possivelmente, isso aconteceu devido à reflexão das ciências humanas e sociais a respeito da educação ambiental, pois perceberam sua necessidade e importância.

Sendo que, agora, ela tornou-se uma dimensão fundamental, com especificidade própria, em que o adjetivo ambiental é um substantivo. Conforme Layrargues, a educação ambiental é um vocábulo composto que envolve os campos 'educação' e 'ambiente' " $O$ adjetivo ambiental designa uma classe de características que qualificam essa prática educativa, diante desta crise ambiental que ora o mundo vivencia" (2009, p.7). Assim, sua práxis aponta para uma tendência de diferenciação, na medida em que se desenvolve e cresce, englobando, ao mesmo tempo, reflexões como miséria e exclusão social com poluição e degradação ambiental.

Essa tendência que começa a ser denominada como "crítica" ou "transformadora" isenta-se de pertencer à neutralidade política, por ir além das consequências da crise ambiental esperadas. Layrargues \& Loureiro (2000) dissertam a respeito disso que:

...essa tendência da educação ambiental (...) deixa de ser politicamente neutra, ao ir além das consequiências da crise ambiental. Consolida uma argumentação que legitima a crítica ao sistema capitalista, evidenciando que a causa da degradação ambiental é a mesma da degradação social. Discute os modos de apropriação e uso privado dos recursos naturais e humanos, aponta os conflitos socioambientais daí advindos, e identificando não apenas a degradação ambiental, mas também as vítimas dos seus efeitos (LAYRARGUES \& LOUREIRO, 2000, p.6).

O Brasil tem realizado e protagonizado esse debate, abrigando uma enorme gama de discussões sobre as especificidades da educação nessa construção. E renomear o vocábulo Educação Ambiental pode significar dois movimentos distintos: um refinamento conceitual baseado no amadurecimento teórico do campo e o estabelecimento de fronteiras identitárias segmentando diversas vertentes (LAYRARGUES, 2009).

Assim, a Educação Ambiental Crítica ${ }^{3}$ apresenta-se com um conteúdo emancipatório, a partir de uma matriz que vê a educação como elemento de transformação social em que as atividades humanas relacionadas ao fazer educativo provocam metamorfoses individuais e coletivas, locais e globais, bem como econômicas e culturais (LOUREIRO, 2004). A Educação Ambiental Crítica busca mostrar o significado e o sentido da revolução para se

\footnotetext{
${ }^{3}$ Segundo Loureiro, In: Identidades da Educação Ambiental Brasileira (2004), a adjetivação 'transformadora' da educação ambiental é estritamente a condição de uma nuance inserida no campo libertário da educação ambiental, no qual se inserem abordagens similares (emancipatória, crítica, popular, ecopedagogia,etc.) que se aproximam na compreensão da educação e da inserção de nossa espécie em sociedade.
} 
concretizar, com base numa transformação integral do ser humano e das condições objetivas de existência, segundo Loureiro:

Entendemos que falar em Educação Ambiental transformadora é afirmar a educação enquanto práxis social que contribui para o processo de construção de uma sociedade pautada por novos patamares civilizacionais e societários distintos dos atuais, na qual a sustentabilidade da vida, a atuação política consciente e a construção de uma ética que se afirme como ecológica sejam seu cerne (LOUREIRO, 2004, p. 90).

Por isso, pensamos que se tivermos mais clareza de qual o papel político da EA, poderemos construir uma proposta educacional de organização dos cidadãos, quanto às questões socioambientais. É importante destacar ainda que iniciar na Educação Ambiental significa começar a refletir sobre os problemas socioambientais a partir daqueles do nosso próprio cotidiano.

Portanto, as possibilidades de se pensar a Educação Ambiental como um movimento significativo partem intrinsecamente de muitos elementos e princípios da Educação Ambiental Crítica, que ajudam a orientar as práticas educativas e a ambientalizar os processos educativos em geral para as relações sociais e com a natureza. Por fim, é importante salientar que a Educação Ambiental não deve ser considerada como a solução para os problemas ambientais, como se a esperança atribuída à educação, por si só, fosse capaz de proporcionar transformações na sociedade, mas sim deve ser entendida como uma das possibilidades importantes entre as diversas outras existentes na sociedade.

\section{Aproximações dos fundamentos de uma Educação Ambiental Crítica com os elementos históricos, epistemológicos e sociológicos das Ações Afirmativas}

Embora no contexto nacional esteja latente a temática das Ações Afirmativas, principalmente a partir da Lei 12.711 que trata sobre modalidades de ingresso nas universidades e institutos federais, bem como outros projetos e ações sendo desenvolvidas, muitas pessoas ainda não entendem ou não compreendem o que são Ações Afirmativas, o que leva, por vezes, ao preconceito por estas políticas. Esse preconceito se manifesta como uma ideia formada antecipadamente sem fundamento crítico ou lógico, resultado de ideias préconcebidas, por posturas intolerantes que não possuem o conhecimento da situação. Segundo o filósofo italiano Norberto Bobbio "O preconceito é uma opinião errônea tomada fortemente por verdadeira, mas nem toda opinião errônea pode ser considerada um preconceito". (BOBBIO, 2002, p.103, 104), isto é, nasce de uma generalização superficial 
acolhida passivamente, que escapa do raciocínio e se instaura como certeza.

Buscando estabelecer aproximações dos fundamentos da Educação Ambiental Crítica com os elementos das Ações Afirmativas é que analisamos que a partir da relação estabelecida dos enfoques do princípio de sustentabilidade, destacados nos documentos supracitados na sessão anterior, as Ações Afirmativas são políticas sistêmicas e estão relacionadas a aspectos econômicos, sociais, culturais e ambientais das comunidades e das pessoas que as utilizam. Assim, se sustentabilidade é dar suporte a alguma ação, as Ações Afirmativas realizam esse trabalho, pois orientam de uma forma socialmente justa e com diversificação cultural.

Neste viés, as Ações Afirmativas tem seus princípios de sustentabilidade, pois surgem para promover a inclusão dos grupos historicamente marginalizados, afirmando suas identidades perante a sociedade em geral e originando assim a diversidade e a pluralidade, principalmente no ensino superior que até pouco tempo era visto como elitista.

Consideramos as discussões sobre educação Ambiental Crítica, importantes para que aconteça a reforma do nosso modo de pensar as Ações Afirmativas, que leve em conta e integre as condições sociais, históricas, culturais, entre outras. Logo, qualquer atividade de cunho social; ambiental; institucional; educacional; cultural; de lazer; atividades inovadoras e criativas são ações que reafirmam posições e fazem com que a sociedade reflita sobre questões como preconceito, diversidade, autonomia e inclusão.

As Ações Afirmativas se constituem numa perspectiva de emancipação do sujeito, em que a busca da superação da relação contraditória opressor-oprimido, consiga atingir uma nova ordem social, construída em conformidade com a liberdade e igualdade. Dessa forma, o que as Ações Afirmativas buscam garantir é o desenvolvimento integral do humano, que consequentemente desenvolve o crescimento local e global em todos os aspectos que possamos imaginar.

Para consolidar essa emancipação é fundamental acreditar em um processo participativo, pois entendemos que o referido processo está fundamentado nas contribuições de Paulo Freire (1987) sobre diretividade, diálogo e humanização, isto é, em ações fundamentadas nos princípios da educação emancipadora e crítica:

Por isto o diálogo é uma exigência existencial. E, se ele é o encontro em que se solidariza o refletir e o agir de seus sujeitos endereçados ao mundo a ser transformado e humanizado, não pode reduzir-se a um ato de depositar ideias de um sujeito no outro, nem tampouco tornar-se simples troca de ideias a serem consumidas pelos permutantes. (FREIRE, 1987, p. 45).

Esse processo valoriza o saber adquirido na experiência social e cultural que 
direcionam para novas aprendizagens e consequentemente, reforçam a necessidade de promoção de políticas que promovam a construção de novas relações sociais e/ou com o mundo. O diálogo, que é base na educação, apresenta-se numa perspectiva transformadora e popular de Educação Ambiental crítica, porque só nos educamos/aprendemos dialogando em um conjunto de relações, pelas quais definimo-nos como seres sociais e planetários. Freire já justificava a visão de educação como um processo dialógico pelo qual nos educamos mutuamente mediados pelo mundo (LOUREIRO, 2004).

Segundo Paulo Freire, em seu livro Pedagogia do Oprimido, é importante defendermos uma pedagogia que promova a emancipação dos sujeitos, seja por intermédio de lutas ou pela sua própria libertação. Contudo, isso só terá significado e sentido se os próprios oprimidos se empenharem na reconstrução de sua humanidade, buscando “[...] a grande tarefa humanística e histórica dos oprimidos-libertar-se a si e aos opressores" (FREIRE, 1987, p.30).

Na tentativa de compreendermos o mundo de forma crítica, se faz necessária uma concepção de que nenhum conhecimento pode ser historicamente, epistemologicamente e sociologicamente pensados fora da vida cotidiana. E a partir dessa compreensão de mundo crítica, abrangemos a realidade em sua totalidade, na tentativa de investigar as contradições nelas existentes, bem como todos os movimentos que subsidiam nossa existência.

Nesse viés, a possibilidade de pensarmos em uma nova sociedade deve considerar que somos seres com culturas, linguagens, racionalidades, éticas e natureza, e por inúmeras razões, entre elas a biológica, nos tornamos parte de um processo histórico-cultural, numa perspectiva ontológica para a Educação Ambiental Crítica. Portanto, acreditamos que nas Ações Afirmativas, enquanto perspectiva emancipatória, que vai ao encontro dos Fundamentos da Educação Ambiental, isto é, uma ação educativa que se desenvolve através de uma prática, na qual valores e atitudes promovem um comportamento rumo a mudanças perante a realidade, gerando a transformação social necessária.

\section{Referências}

BOBBIO, Norberto. Elogio da Serenidade e outros escritos morais. Tradução Marco Aurélio Nogueira. São Paulo: Editora UNESP, 2002.

BRASIL. Rio 92: Tratado de EA para sociedades sustentáveis e responsabilidade global. Rio de Janeiro, 1992. Disponível em https://www.pensamentoverde.com.br/sustentabilidade/tratado-educacao-ambientalsociedades-sustentaveis-responsabilidade-global/ , acesso em 10 de dezembro de 2017. 
BRASIL. Política Nacional de Educação Ambiental. Lei nº 9795/1999, de 27 de abril de 1999, que dispõe sobre a educação ambiental e institui a Política Nacional de Educação Ambiental e dá outras providências. Brasília, DF. Disponível em http://www.planalto.gov.br/CCIVil_03/LEIS/L9795.htm, acesso em 01 de outubro de 2017.

BRASIL. Diretrizes curriculares da Educação Ambiental. Resolução No 2, de 15 de Junho de 2012. Disponível em: http://conferenciainfanto.mec.gov.br/images/conteudo/ivcnijma/diretrizes.pdf , acesso em 05 de dezembro de 2017.

BRASIL. Lei $\mathrm{n}^{\mathrm{o}}$ 12.711, de 29 de agosto de 2012. Dispõe sobre o ingresso nas universidades federais e nas instituições federais de ensino técnico de nível médio e dá outras providências. Disponível em: http://www2.camara.leg.br/legin/fed/lei/2012/lei-12711-29-agosto-2012774113-publicacaooriginal-137498-pl.html, acesso em 01 de dezembro de 2015.

CARSON, Rachel. Primavera silenciosa. São Paulo: Melhoramentos, 1969.

ESTOCOLMO. Declaração da Conferência das Nações Unidas sobre o Meio Ambiente Humano - 1972. Disponível em: https://www.apambiente.pt/_zdata/Politicas/DesenvolvimentoSustentavel/1972_Declaracao_ Estocolmo.pdf, acesso em acesso em 10 de dezembro de 2017.

FONSECA, Dagoberto José da. Políticas públicas e Ações afirmativas. São Paulo: Selo Negro, 2009.

FREIRE, Paulo. Pedagogia do oprimido. 17 ed. Rio de Janeiro: Paz e Terra, 1987.

GADOTTI, Moacir. Educação e poder: Introdução à Pedagogia do Conflito. São Paulo: Ed. Cortez. 9 ed, 1989.

GUIMARÃES, Mauro. A formação de educadores ambientais. Campinas, SP: Papirus (Coleção Papirus Educação) 2004, 171 p.

LAYRARGUES, Philippe Pomier. Educação Ambiental com compromisso social: o desafio da superação das desigualdades. In: Repensar a Educação Ambiental: um olhar crítico. São Paulo: Cortez, 2009.

LEFF, Enrique. Epistemologia Ambiental. 5ed. São Paulo: Cortez Editora, 2002.

LEFF, Enrique. Racionalidade Ambiental: a reapropriação social da natureza. Rio de Janeiro: Civilização Brasileira, 2006.

LEFF, Enrique. Discursos sustentáveis. São Paulo: Cortez, 2010.

LOUREIRO, Carlos Frederico. Trajetórias e Fundamentos da Educação Ambiental. São Paulo: Cortez, 2004.

LOUREIRO, Carlos Fraderico; LAYRARGUES, Philippe Pomier. A Educação Ambiental nos anos 90: mudou, mas nem tanto. Políticas Ambientais. Vol 9, n 25. Rio de Janeiro, 2000.

MINAYO, Marília Cecília de Souza. O desafio do conhecimento: Pesquisa Qualitativa em 
Saúde.(12ª edição). São Paulo: Hucitec-Abrasco, 2010.

PEREIRA, Vilmar Alves. Ecologia Cosmocena: a redefinição do espaço humano no cosmos. 1 ed. Juiz de Fora, MG: GARCIA Edizioni, 2016.

SAUVÉ, Lucie. Uma cartografia das correntes em Educação Ambiental. In: SATO, Michele; CARVALHO, Isabel (orgs.). Educação Ambiental: pesquisa e desafios. Porto Alegre: Artmed, 2005, p. 18 - 44.

TBILIZI. Recomendações da Conferência Intergovernamental sobre Educação Ambiental aos Países Membros (Tbilisi, CEI, de 14 a 26 de outubro de 1977). Disponível em: http://www.meioambiente.pr.gov.br/arquivos/File/coea/Tbilisi.pdf

VASCONCELLOS, H. S. R. A pesquisa-ação em projetos de Educação Ambiental. In: PEDRINI, A.G. (org.). Educação Ambiental: reflexões e práticas contemporâneas. 5ed. Petrópolis: Vozes, 2002, p. 260-289.

odelo para Sites). 